\title{
14668 \\ COMPARATIVE REPRODUCTIVE BIOLOGY OF FOUR BLUE TIT POPULATIONS IN THE NETHERLANDS
}

\author{
Johan H. van BALEN and Roel P.J. POTTING \\ Institute for Ecological Research, Boterhoeksestraat 22, PO BOX 40, \\ 6666 GA Heteren, The Netherlands
}

After a long period in which research on the population biology of holenesting birds was mainly conducted on the Great Tit (Parus major), recently more attention is being given to its counterpart, the Blue Tit (Parus caeruleus). This is partly due to the increasing number of studies from the mediterranean region (Blondel et al. 1987), where the Blue Tit is often the most numerous tit species. As this species seems to be a promising subject for a comparative demographical study over a large area of Europe, an analysis of data collected in several populations from the Netherlands is of interest. Correlative studies in contrasting habitats can give us clues about the factors that influence parameters such as date of egglaying, clutch size and breeding success, but they need experimental verification.

In this paper we will first compare the values obtained for each parameter in the various areas. Next we will examine if there are trends in the course of the study period, and analyse the correlations of the annual figures for the different areas. This will show us whether the factors that influence the parameter under study are general or rather local factors. Thirdly the relationships with environmental variables and with population characteristics will be considered, and the presumed causes of the established relationships will be discussed. If appropriate, a comparison will be made with the Great Tit, or Great Tit parameters will be used in the analyses.

\section{STUDY AREA AND METHODS}

Data were collected in four areas, distributed throughout the country, two are mature deciduous oak forests and the others are a mixture of deciduous and coniferous forest plots:

Vlieland: all the wooded areas ( $292 \mathrm{ha})$ on the island $(53.17 \mathrm{~N}, 5.03 \mathrm{E})$ are included. The forest was planted about 1900, and is mainly Pine (Pinus ssp.) with local patches of Birch (Betula ssp.), Oak (Quercus robur), and other deciduous trees. Since the early sixties selective felling has increased the proportion of deciduous trees. The number of nestboxes has gradually increased from 125 (1956) to 200 (1966) and to 350 (1986), to keep in pace with the increased suitability of the habitat. For some purposes the total area is divided into Vlieland-East (the 214 ha forest north of the village) and Vlieland-West (the remaining four small forest plots). The vegetation of the two areas is 
similar, but the population in East is closer to the village, and therefore could profit more from food provision by man in winter.

Hoge Veluwe: an area situated in the southern part of the National Park $(52.03 \mathrm{E}, 5.51 \mathrm{~N})$. From 1960 to 1972 the study area was about 320 ha and the plantations were $60 \%$ pine and $40 \%$ mixed coniferous-deciduous woodland, with between 215 and 325 nestboxes. From 1973 onward the area was reduced to 165 ha, with an increased proportion of deciduous trees, and about 370 nestboxes. Extra seed food was provided in the winters of 1966/1967 to 1975/1976.

Oosterhout: a small (11.4 ha) deciduous wood with predominantly mature oaks and dense undergrowth. It is (at $51.52 \mathrm{~N}, 5.50 \mathrm{E}$ ) isolated from other woodland by agricultural land. Number of nestboxes increased from 29 (1959) to 78 (1965) and finally about 135 (1966 to 1986). Data for 1982 are not available as Blue Tits were experimentally removed in spring.

Liesbos: study area (18 ha) is part of 190 ha medium-aged to mature oak forest in the southern part of the country $(51.35 \mathrm{~N}, 4.42 \mathrm{E})$. Since 1957 there have been about 97 nestboxes.

In three areas nestboxes were inspected at least once a week during the breeding season, but in Liesbos in some years only data on laying date and clutch size were collected. Nestlings were ringed in Vlieland (all years), Hoge Veluwe (from 1960) and Oosterhout (most years). Blue Tit parents were identified in Vlieland (all years), Hoge Veluwe (up to 1970) and Oosterhout (mainly in 1981 and 1987). For the analysis, data were used from the period 1965-1986.

\section{BREEDING DENSITY}

Blue Tit densities are highest in the two deciduous woods, Oosterhout (mean 17.0, S.D. 4.1 first clutches/10 ha) and Liesbos (mean 12.1, S.D. 3.1), and much lower in the mixed forests (Hoge Veluwe mean 1.9, S.D. 1.0, Vlieland-West mean 2.3, S.D. 1.0, Vlieland-East mean 0.5, S.D. 0.3). Differences between areas are more extreme than in the Great Tit that has the same overall pattern although at a higher level. The annual density figures in the deciduous habitats are less variable (coefficient of variation $=24-26 \%$ ) than those in the mixed habitats (C.V. $=44-60 \%)$, suggesting again that the former are the more favourable habitats.

The two parts of Vlieland show a fourfold difference in Blue Tit breeding density in favour of the part with the lowest Great Tit density, suggesting that interspecific competition may play a role. Here, too, for both species the part with the highest density is the one where density is least variable.

Trends in Blue Tit density throughout the study period differ strikingly between areas (Fig. 1). In the two oak forests there is neither increase nor decrease, but in the other areas there is a distinct increase. The Blue Tit population of the island of Vlieland is fairly new, the first pair in nestboxes being recorded in 1957. Population increase started in 1965, coinciding with a sharp increase in Great Tit numbers which was ascribed to a sudden 


\section{DENSITY}
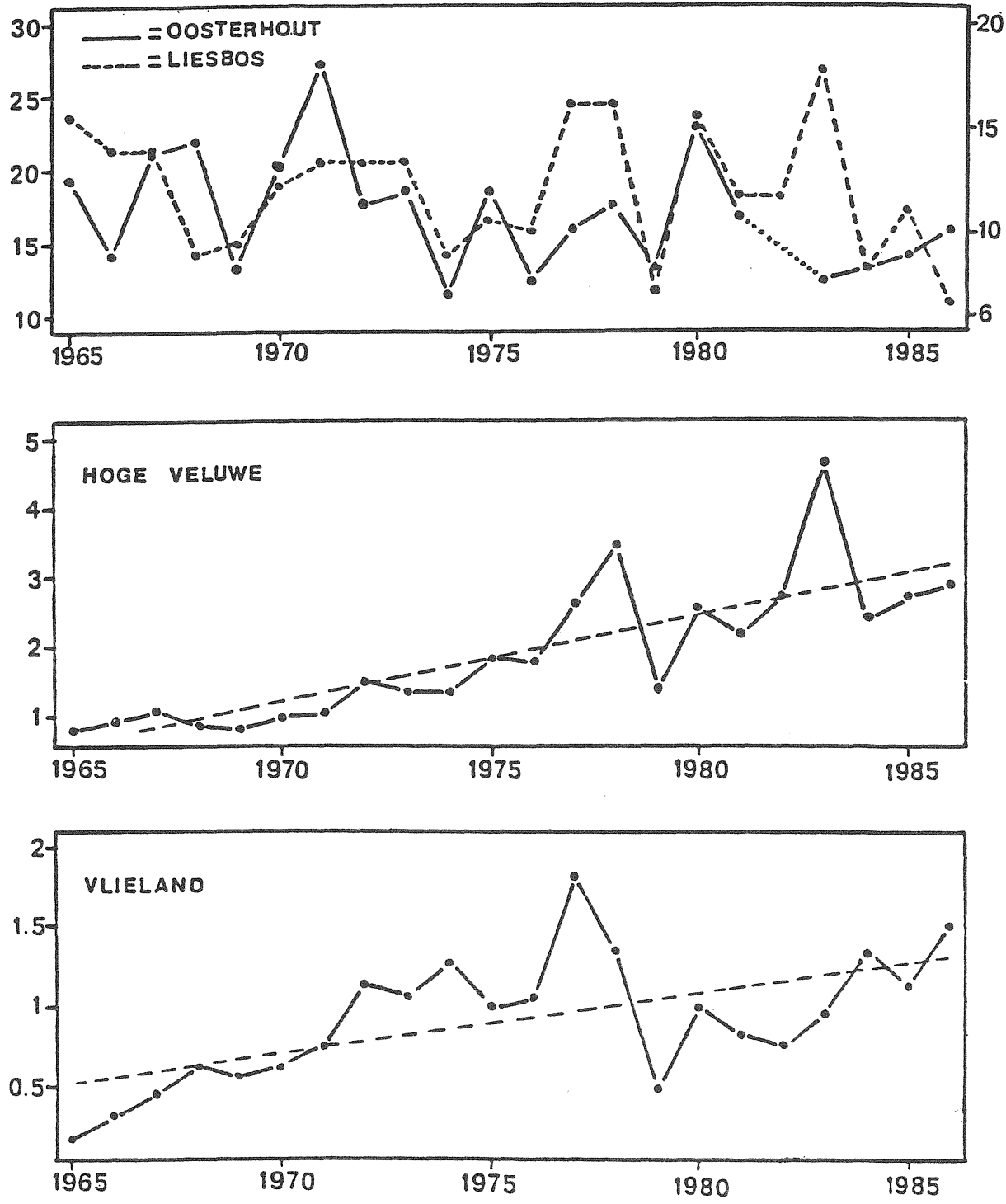

Fig. 1. Fluctuations of Blue Tit density (no. of first broods per 10 ha) from 1965 to 1986 in four areas, with significant regression lines. Upper panel: left axis for Oosterhout, right axis for Liesbos.

improvement of the habitat through selective felling (Kluyver 1971). In addition, presumably feeding by man in winter has increased over the years, possibly leading to increased survival in winter. Both factors may have contributed to the increase in tit density in Vlieland, and, to a lesser extent, in Hoge Veluwe. 
The fluctuations in density in the two oak forests are more or less parallel. In general, the annual density figures are positively correlated for most pairs of areas, but this is partly due to the general trends described above. The correlations between the density changes from one year to the next are given in Table I. The two parts of Vlieland are considered separately, as their densities are so markedly different. It appears that the density changes in Oosterhout, Liesbos and Hoge Veluwe are positively correlated. The correlation coefficients for Vlieland-West are somewhat lower, but significant in two out of three cases. Density changes in the low-density area Vlieland-East are not correlated with changes in the other areas, not even with the neighbouring area Vlieland-West. We conclude that density changes are to a large extent determined by general factors, but that local factors must play a greater role in Vlieland-East.

Table 1. Correlation coefficients for density changes (absolute difference in density from one year to the next), comparison of three areas and the two subareas of Vlieland.

\begin{tabular}{|c|c|c|c|c|}
\hline & Liesbos & Hoge Veluwe & Vlieland-West & Vlieland-East \\
\hline Oosterhout & $0.595 * *$ & $0.522 *$ & 0.301 & -0.033 \\
\hline Liesbos & $\mathrm{x}$ & $0.845 * * *$ & $0.513^{*}$ & 0.028 \\
\hline Hoge Veluwe & & $\mathrm{x}$ & $0.533^{*}$ & 0.193 \\
\hline Vlieland-West & & & $\mathrm{x}$ & 0.135 \\
\hline
\end{tabular}

Note: $*$ p $<.05, * *: \mathrm{p}<.01, * *: \mathrm{p}<.001$

The effect of environmental factors on breeding density was analysed by multiple regression analysis. As independent variables were included: year number, Hellmann figure (i.e. the absolute sum of all daily mean temperatures below $0^{\circ} \mathrm{C}$, measured over the months November-March at De Bilt), and a figure for the Beech Crop Index (BCI). Moreover, we included Great Tit density figures to check if there are indications for interspecific competition. Table II shows that no significant relationships were found in the two oakwoods, though in Liesbos the effect of winter severity was nearly significant. In the mixed woods, there was a very significant increase in density with year number, confirming earlier results, and density was also lower after severe winters. A similar analysis for density changes from one year to the next did not give significant results for the variables year number, Hellmann figure and BCI. For the two oakwoods it showed that Blue and Great Tit densities changed in the same direction (cf.Perrins 1979).

In summary, there are large differences in density between areas, probably connected with food availability. Density has increased markedly over the years in the two low-density areas, for as yet unknown reasons. In these areas, 
density fluctuates more than in the high-density areas, and it is influenced by winter severity. In the latter areas, fluctuations of Blue and Great Tit run in parallel.

Table II. Results of multiple regression analysis of Blue Tit breeding density in four areas. Data from 1965 - 1986. P-values and $\mathrm{r}^{2}$, obtained after elimination of the non-significant variables, are given.

\begin{tabular}{|c|c|c|c|c|c|}
\hline Area & year & $\begin{array}{l}\text { Hellmann } \\
\text { figure }\end{array}$ & $\mathrm{BCI}$ & $\begin{array}{c}\text { GT } \\
\text { density }\end{array}$ & $r^{2}$ \\
\hline Oosterhout & n.s. & n.s. & n.s. & n.s. & .1468 \\
\hline Liesbos & n.s. & .0512 & n.s. & n.s. & .1771 \\
\hline Hoge Veluwe & .0000 & .0368 & n.s. & n.s. & .7324 \\
\hline Vlieland & .0002 & .0187 & n.s. & n.s. & .5466 \\
\hline sign & pos & neg & - & - & - \\
\hline
\end{tabular}

\section{DATE OF LAYING}

The mean laying dates of the first clutches are presented in Table III. Differences between areas were analysed with a paired t-test on the annual means.

Table III. Mean laying date of first clutches of the Blue Tit (mean of annual means) in four areas and the two parts of Vlieland. Dates counted from 1 April $=1$.

\begin{tabular}{|c|c|c|c|}
\hline & mean date & S.D. & C.V.(\%) \\
\hline Oosterhout & 19.63 & 4.97 & 25.3 \\
\hline Liesbos & 21.20 & 4.79 & 22.6 \\
\hline Hoge Veluwe & 26.20 & 4.11 & 15.7 \\
\hline Vlieland & 26.20 & 2.83 & 10.8 \\
\hline Vlieland-West & 24.96 & 3.09 & 12.4 \\
\hline Vlieland-East & 27.94 & 3.30 & 11.8 \\
\hline
\end{tabular}


Mean laying dates of the Blue Tit differ between areas by as much as 8.3 days, 4.4 days more than for the Great Tit. Differences between areas were in most cases highly significant, except for the comparison Hoge Veluwe - Vlieland (either West or East). Blue Tits in oak forests lay about six days earlier than those in mixed forests, and show more variability between years, as seen from the coefficients of variation. period.

Mean laying dates did not change significantly in the course of the study

The most likely factors that could explain between-area differences in mean laying date are differences in ambient temperature in spring, and differences in food availability (Clamens and Cramm, in Blondel et al. 1987). As there are appreciable differences in temperature in spring between the Northern and the Southern parts of the country (up to $3^{\circ} \mathrm{C}$ for the maximum and the minimum temperatures in March and April), this factor must be taken into account. Figure 2 gives the calculated regression lines between mean temperature in the period from 10 March and 20 April and mean laying date.

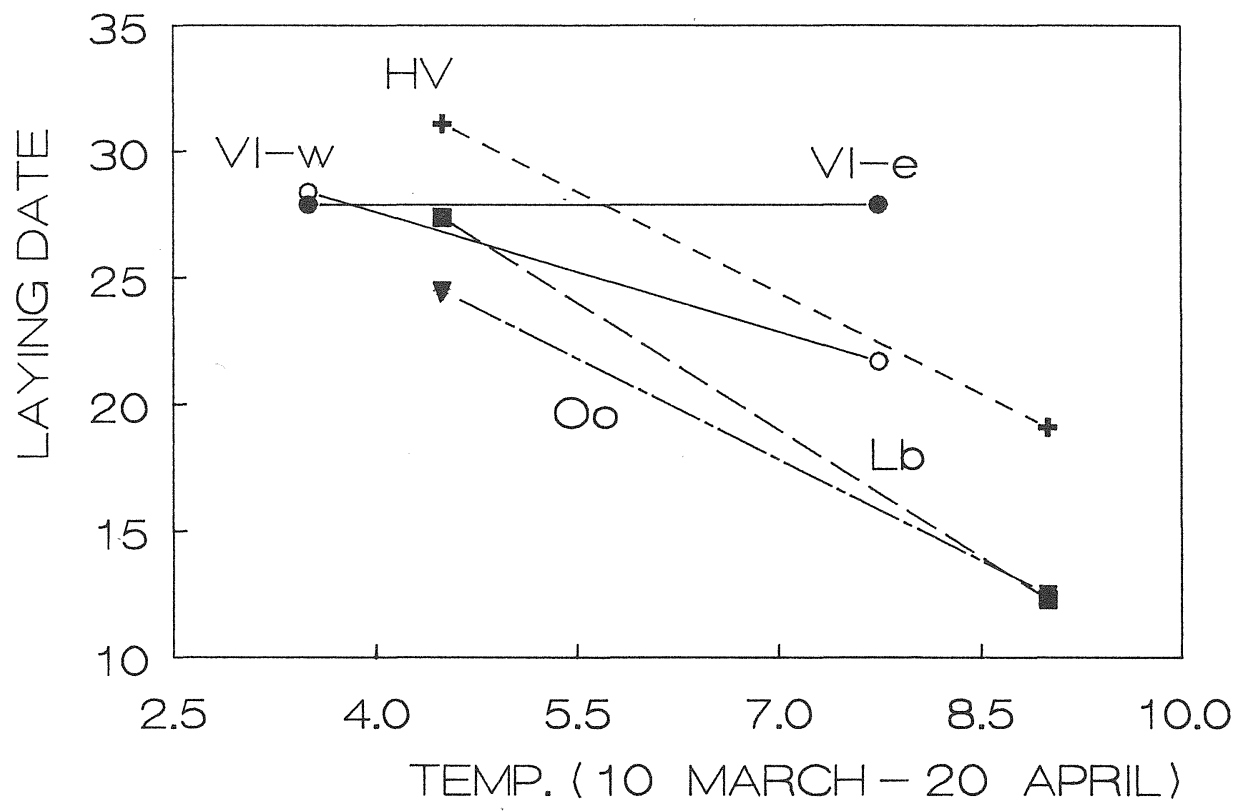

Fig. 2. Regression lines of annual mean laying date of the Blue Tit against ambient temperature in the period from 10 March up to 20 April. Temperature data were taken from De Kooy $(52.55 \mathrm{~N}, 4.48 \mathrm{E})$ for Vlieland, and from De Bilt $(52.06 \mathrm{~N}, 5.10 \mathrm{E})$ for the other study areas. Regression equations: for Oosterhout (Oo): $\mathrm{Y}=36.42-.664 \mathrm{X}$ $(p=.0015)$, for Liesbos $(L b): Y=42.42-.836 X(p=.0000)$, for Hoge Veluwe (HV): $\mathrm{Y}=43.09-.666 \mathrm{X}(\mathrm{p}=.0000)$, for Vlieland-West $(\mathrm{VL}-\mathrm{w})$ : $\mathrm{Y}=33.96-.395 \mathrm{X}(\mathrm{p}=.0110)$, Vlieland-East $(\mathrm{VL}-\mathrm{e}): \mathrm{p}=.4218$, n.s. 
They were significant for all areas except Vlieland-East. Part of the betweenarea differences, e.g. the late laying in Vlieland, can be ascribed to the low prevailing temperatures, but this is not the whole story. Over a large range of temperatures the laying dates in the two oak forests are earlier than those in the mixed forests, indicating that other factors play an additional role, e.g. food availability: Other indications that factors other than ambient temperature play a role are the significant difference in laying date between the two parts of Vlieland, and the difference between Oosterhout and Liesbos. On the basis of temperature alone we would not expect the Blue Tits in Oosterhout to lay earlier, Liesbos being the more southerly location.

The annual mean laying dates in the various areas are mutually correlated (Table IV), as expected from the overriding effect of temperature, but Vlieland-East is an exception: the only significant correlation is with VlielandWest. This corresponds with the absence of a correlation with temperature in the former area.

Table IV. Correlation coefficients for annual mean laying dates in three areas and the two parts of Vlieland.

\begin{tabular}{|c|c|c|c|c|}
\hline & Liesbos & Hoge Veluwe & Vlieland-West & Vlieland-East \\
\hline Oosterhout & $0.820^{* * * *}$ & 0.676 *** & $0.519 *$ & 0.278 \\
\hline Liesbos & $\mathrm{x}$ & $0.768^{* * *}$ & $0.441^{*}$ & -0.035 \\
\hline Hoge Veluwe & & $\mathrm{x}$ & 0.341 & 0.122 \\
\hline Vlieland-West & & & $\mathrm{x}$ & $0.563^{* *}$ \\
\hline
\end{tabular}

Note: ${ }^{*}: \mathrm{p}<.05,{ }^{* *}: \mathrm{p}<.01,{ }^{* * *}: \mathrm{p}<.001$.

The annual mean laying dates of Blue and Great Tit are strongly correlated within all areas. This is not surprising as the laying dates of both species depend to a large extent on ambient temperature in March and April (Fig. 2, see also van Balen 1973 and Schmidt 1984).

In mixed forest the laying dates of the two species are not different, but in oak forest Blue Tits lay on average 3 to 4 days earlier than Great Tits. Such a difference was also found by Dhondt et al. (1984). Oakwood is the habitat with the highest breeding density for both species. If this difference is related to density one would expect a similar correlation between years within one area. For the three areas and the two parts of Vlieland, correlations were computed between the difference in laying date of the two species and their respective densities. In two of the ten cases a significant correlation was obtained. The data for Hoge Veluwe and Vlieland-West do indeed show the expected relationship: in high density years the Blue Tits lay earlier than the Great Tits but in low-density years the difference is reversed (Fig. 3). 
DIFF. LAYDATE BT - GT

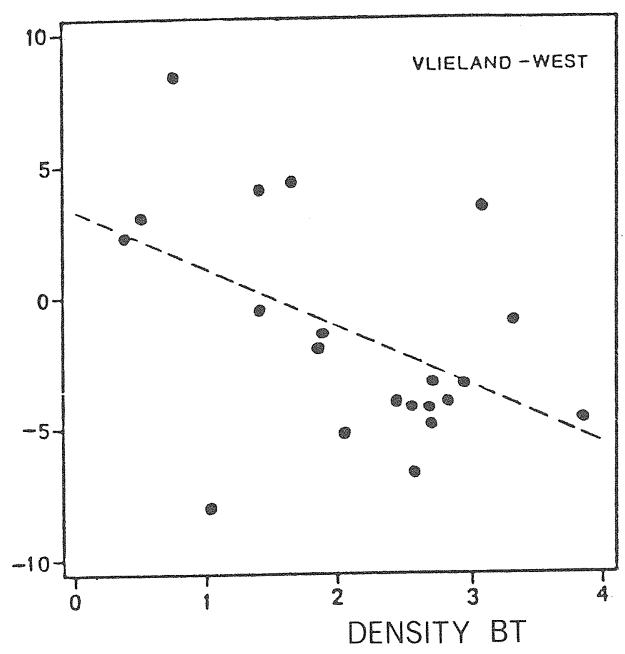

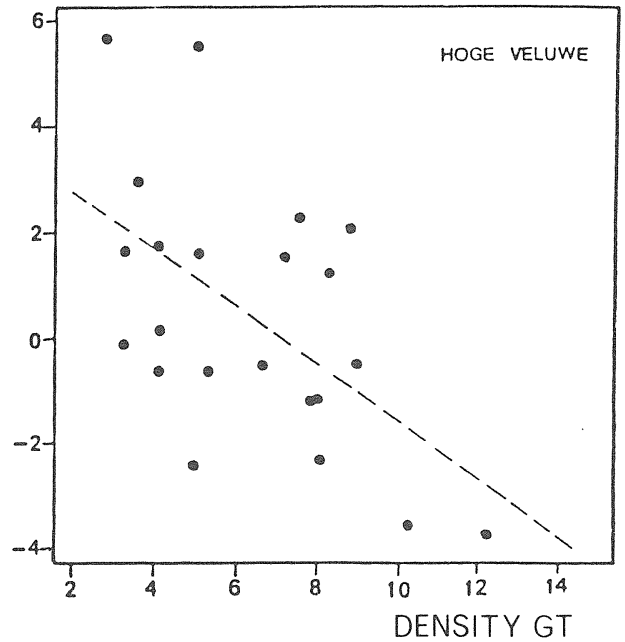

Fig. 3. Correlation between the difference in laying date between Blue and Great Tit (negative $=$ Blue Tit earlier) and breeding density.

We have shown earlier that Blue 'Tit laying dates in the two parts of Vlieland differ significantly. It appears that at least part of this difference is caused by the differential age composition of the two sub-populations. In Vlieland first-year females start egglaying on average 2.1 days later than older females $(t=3.65, n=377, p<.001)$. Not only are most of the females in Vlieland-East yearlings, and lay their eggs correspondingly later than the older females, but also the difference in laying date between East and West is larger in years when the age difference is greater (Fig. 4).

\section{CLUTCH SIZE}

The mean size of the first clutches of the Blue Tit in the four areas and in the two subareas of Vlieland is given in Table V. Differences between the areas were tested with a paired t-test on the annual means, excluding years with fewer than five clutches.

Clutches are largest in the two oak forests, significantly smaller in Vlieland, and smaller still in Hoge Veluwe. All differences are significant except those between Oosterhout and Liesbos, and between Vlieland-West and East.

There is no consistent increasing or decreasing trend in clutch size in the course of the study period, despite the steadily increasing breeding density in Hoge Veluwe and Vlieland.

The annual variation in clutch size is large (Table $V$ ). The annual values for the various areas are in most cases not correlated, not even the figures for Vlieland-West and East. Presumably clutch size is to a large extent determined 


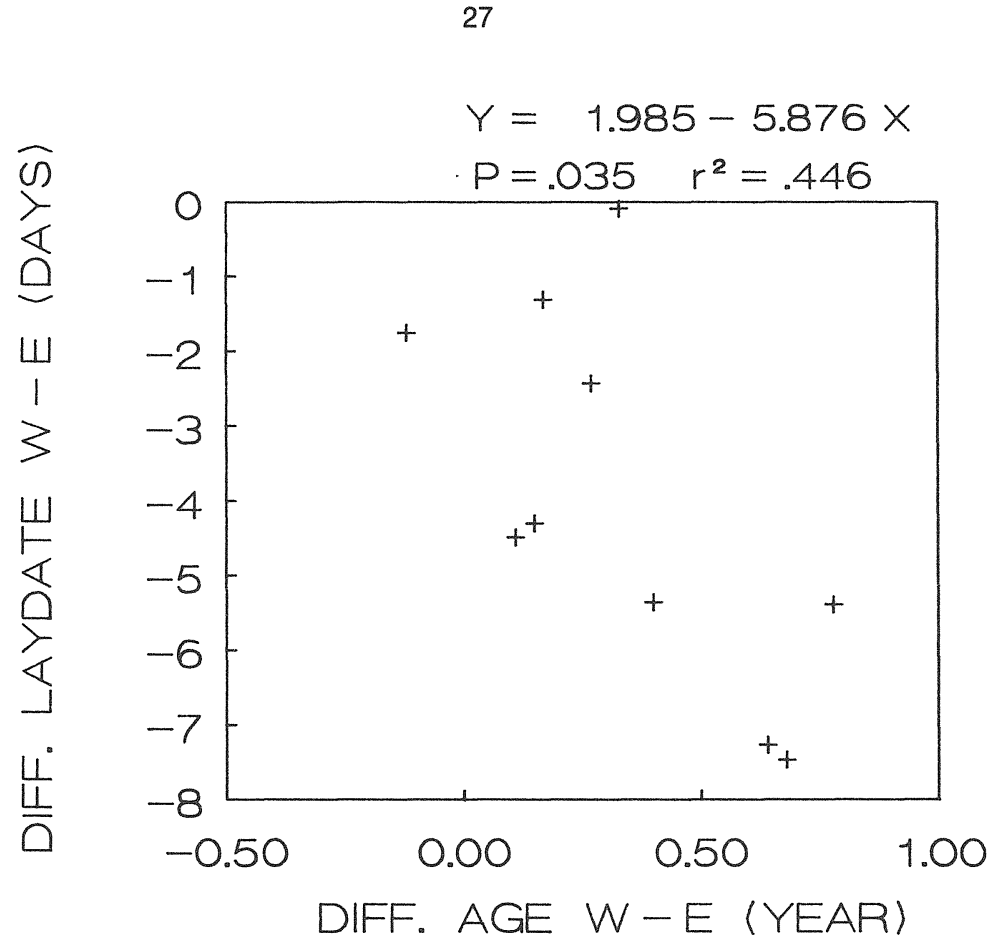

Fig. 4. Relationship between the difference in laying date of the Blue Tit in Vlieland-West and -East, and the age difference of the females in these two subareas. Data from 1977-1986.

Table V. Size of first clutches of the Blue Tit in four areas and in the two parts of Vlieland. Mean of annual means, and highest and lowest value.

\begin{tabular}{|c|c|c|c|c|c|}
\hline Area & mean & S.D. & C.V.(\%) & $\min$. & $\max$. \\
\hline Oosterhout & 11.57 & 0.64 & 5.5 & 10.4 & 12.8 \\
\hline Liesbos & 11.94 & 0.64 & 5.4 & 10.8 & 13.3 \\
\hline Hoge Veluwe & 10.61 & 0.77 & 7.3 & 9.0 & 11.9 \\
\hline Vlieland & 11.20 & 0.38 & 3.4 & 10.7 & 12.2 \\
\hline Vlieland-West & 11.22 & 0.42 & 3.7 & 10.5 & 12.2 \\
\hline Vlieland-East & 11.21 & 0.72 & 6.4 & 9.5 & 12.6 \\
\hline
\end{tabular}

by local factors. The exception is formed by the two oak forests $(r=.529$, $\mathrm{p}<.05$ ), where conditions are presumably more alike than those in the other areas.

Factors that might influence annual and local variation in clutch size include breeding density, date of laying and food availability. There is no information on the annual variation in food availability in the laying season. For each of the four areas, variations in the annual mean figures for clutch size 
were analysed by regression. Density figures for both Blue and Great Tit were taken as independent variables, together with the mean laying date and the year number. In none of the areas is there a correlation with the average date of laying in the year concerned: clutch size is similar in early and late years. In Oosterhout clutch size increased through the years, but the relationship was hardly significant $(p=.04)$. In the other areas there were no trends with time, and clutch size was also not related to Blue or Great Tit density. A similar analysis was performed with the change in clutch size from one year to the next as the dependent variable, and the corresponding change in breeding density (plus year number and laying date) as independent variables. Here, it appeared that the number of eggs is in some subtle way affected by density changes: in Oosterhout and Liesbos there is a significant negative relationship between change in Blue Tit clutch size and the corresponding change in Great Tit breeding density (for Oosterhout: $p=.0017, r^{2}=.450$; for Liesbos: $p=.0006$, $\mathrm{r}^{2}=.506$ ). A similar result was obtained by Clamens and Cramm (in Blondel et al. 1987) in a Holm Oak wood in southern France.

A correlation such as this could be partly based on differences in age composition that go hand in hand with density changes. In dense populations there is a higher proportion of yearling females, and yearlings (in Vlieland) lay on average 0.5 eggs less than older birds $(t=3.70, p<.001)$.

Clutch size decreases strongly in the course of the laying season. This also applies to first clutches (Fig. 5). In all four areas there is a significant (Oosterhout, Vlieland) or highly significant (Liesbos, Hoge Veluwe) decrease with relative laying date. The decrease is strongest in Hoge Veluwe, corresponding with earlier findings on the Great Tit (van Balen 1973). In Vlieland the decrease is very small, and is not significant in all years except one. Assuming that the seasonal decline in clutch size is ultimately linked to the survival chances of the nestlings, we expect that survival chances in Vlieland should not deteriorate as quickly as they do in the other areas. This will be confirmed in the next section.

So far we have seen that there are differences in clutch size between the areas, that cannot be explained by factors like laying date and breeding density. Furthermore, annual variation in clutch size is large, is not correlated between areas and cannot be explained by variation in laying date and breeding density, except that increases in Great Tit density reduce the number of Blue Tit eggs in high-density areas. Clutch size depends more on local than on general factors.

\section{BREEDING SUCCESS}

Failure of eggs to produce fledglings falls into two categories: total and partial losses. Total losses are often caused by predation or unfavourable weather, and are therefore erratic in time and space. Partial losses are often connected with (quantitative or qualitative) food shortage and indicate the factors that can influence brood size. 


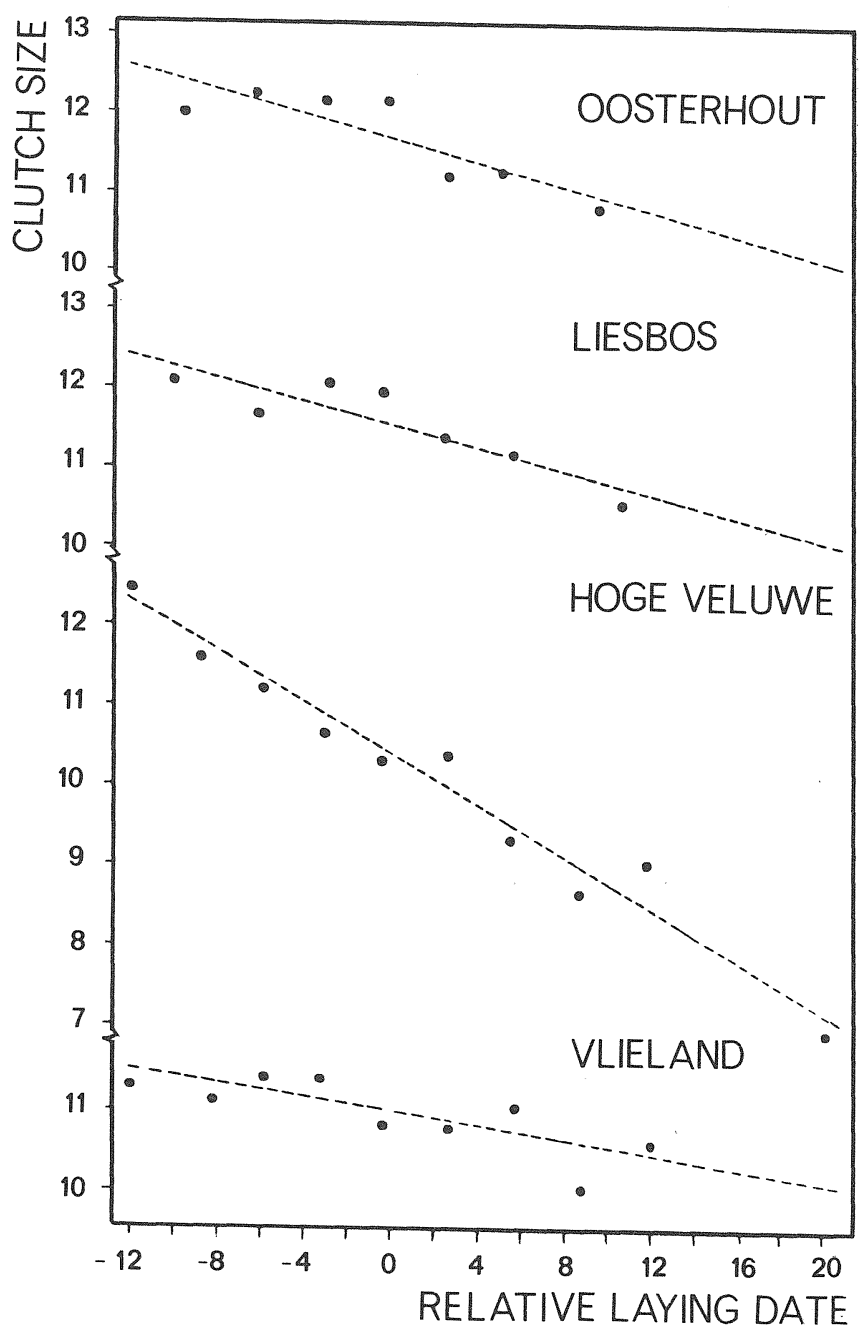

Fig. 5. Decrease in size of first clutches with relative laying date in four areas. $(0=$ mean laying date in the year concerned). Data from $1974-1986$.

Table VI gives the percentage of successful clutches for the three areas for which adequate data are available. The mean percentages for the three areas do not differ. In Oosterhout, success seems to be rather variable, due to two years in which there was heavy predation and some damage by people. The annual figures for percentage success are not correlated to the corresponding figures for partial success that will be discussed hereafter.

For all clutches that produced at least one fledgling we computed three measures of reproductive success: hatching success (proportion of eggs hatched), fledging success (proportion of young fledged) and breeding success, being the product of hatching and fledging success. 
Table VI. Proportion of successful clutches in three areas in the years 1965 1986. Successful $=$ at least one fledgling.

\begin{tabular}{|c|c|c|c|c|c|}
\hline Area & mean & S.D. & $\mathrm{n}$ & $\min$. & $\max$ \\
\hline Oosterhout & .853 & .209 & 21 & .214 & 1.000 \\
\hline Hoge Veluwe & .875 & .063 & 22 & .693 & .979 \\
\hline Vlieland & .821 & .104 & 22 & .571 & 1.000 \\
\hline
\end{tabular}

Table VII gives the average values of success together with the mean number of fledged young in successful first broods. It shows clearly that reproductive success is highest in the oak forest Oosterhout, that hatching success is lower in the two mixed forests and that fledging success is lowest in Vlieland. Breeding success in Vlieland is only $74 \%$ of that in Oosterhout and the corresponding value for the number of fledged young per successful brood is $72 \%$. Not only do the mean values decrease from Oosterhout to Vlieland, but there is also an increase in variability, as measured by the coefficients of variation. Both findings demonstrate that conditions for incubating eggs and rearing nestlings are best in Oosterhout and worst in Vlieland.

Table VII. Reproductive success in three areas. All clutches with at least one fledgling are included. $N=277$ (Oosterhout), 600 (Hoge Veluwe), 425 (Vlieland).

\begin{tabular}{|c|c|c|c|c|c|c|c|c|c|}
\hline & \multicolumn{2}{|c|}{ Oosterhout } & C.V. & $\begin{array}{l}\text { Hoge } \\
\text { mean }\end{array}$ & $\begin{array}{l}\text { Veluw } \\
\text { S.D }\end{array}$ & C.V & $\begin{array}{l}\text { Vliela } \\
\text { mean }\end{array}$ & S.D. & C.V. \\
\hline Hatching success & 0.92 & 0.11 & 12.0 & 0.84 & 0.18 & 21.4 & 0.81 & 0.20 & 24.7 \\
\hline Fledging success & 0.96 & 0.07 & 7.3 & 0.92 & 0.14 & 15.3 & 0.82 & 0.20 & 24.4 \\
\hline Breeding success & 0.89 & 0.14 & 15.7 & 0.77 & 0.21 & 27.3 & 0.66 & 0.20 & 30.3 \\
\hline $\begin{array}{l}\text { igs per } \\
\text { ful clutch }\end{array}$ & 10.2 & 2.12 & 20.8 & 8.4 & 2.95 & 35.1 & 7.3 & 2.73 & \\
\hline
\end{tabular}

Fledging success did not show a decreasing or increasing trend through the years, but hatching success (and consequently breeding success) decreased significantly in Hoge Veluwe and Vlieland (Fig. 6). The presumed cause of this phenomenon will be treated in the Discussion.

When the annual values for the measures of breeding success are compared between the three areas we do not find any significant correlations. Within areas, however, hatching and fledging success are usually correlated: for 


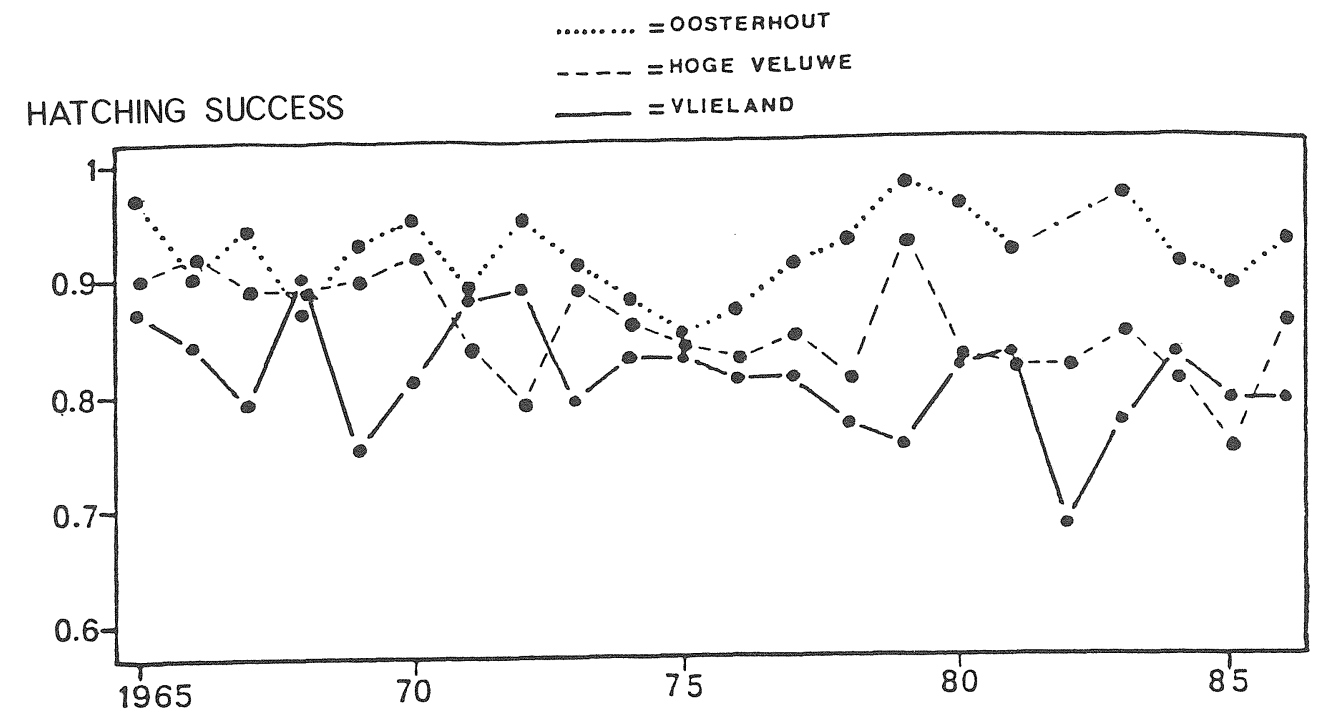

Fig. 6. Trends of hatching success in the course of the years. Those in Hoge Veluwe $(\mathrm{Y}=0.9047-0.0004 \mathrm{X}, \mathrm{p}=0.0026)$ and in Vlieland $(\mathrm{Y}=0.8513-0.0004 \mathrm{X}, \mathrm{p}=0.0344)$ decrease significantly.

Oosterhout $r=0.497(p=.022)$, for Hoge Veluwe $r=0.586(p=.003)$, but for Vlieland: $r=0.297 \quad(p=.180)$. These findings indicate that breeding success mainly depends on local rather than on general conditions.

Breeding success varies strongly during the season. Figure 7 shows the two components of breeding success in relation to relative hatching date. Dates over 25 refer to repeat and second clutches. In Oosterhout hatching success declines slightly and fledging success more strongly during the first-brood period. In Hoge Veluwe hatching success shows a steep decline during the first month and increases greatly in the late broods, and fledging success declines throughout the season. Results from Vlieland deviate from this pattern: during the period of the first broods both hatching and fledging success increase. The most consistent differences between the areas are found for fledging success. Probably, changes in food availability for the nestlings during the breeding season do not vary in parallel in the three areas.

A regression analysis of the breeding success of individual first broods, with relative hatching date and clutch size as independent variables, confirmed that breeding success was negatively related to date in Oosterhout and Hoge Veluwe, and positively in Vlieland.

In order to analyze the relationships of breeding success with breeding density and clutch or brood size, multiple regressions were performed with the annual means, including the number of the year and the mean date of laying as independent variables. The results (Table VIII) differ for the three areas. In the oak forest there is a positive correlation between hatching success and mean clutch size: hatching success (and hence also breeding success) is greater in years when clutches are large. This correlation also holds when all non- 


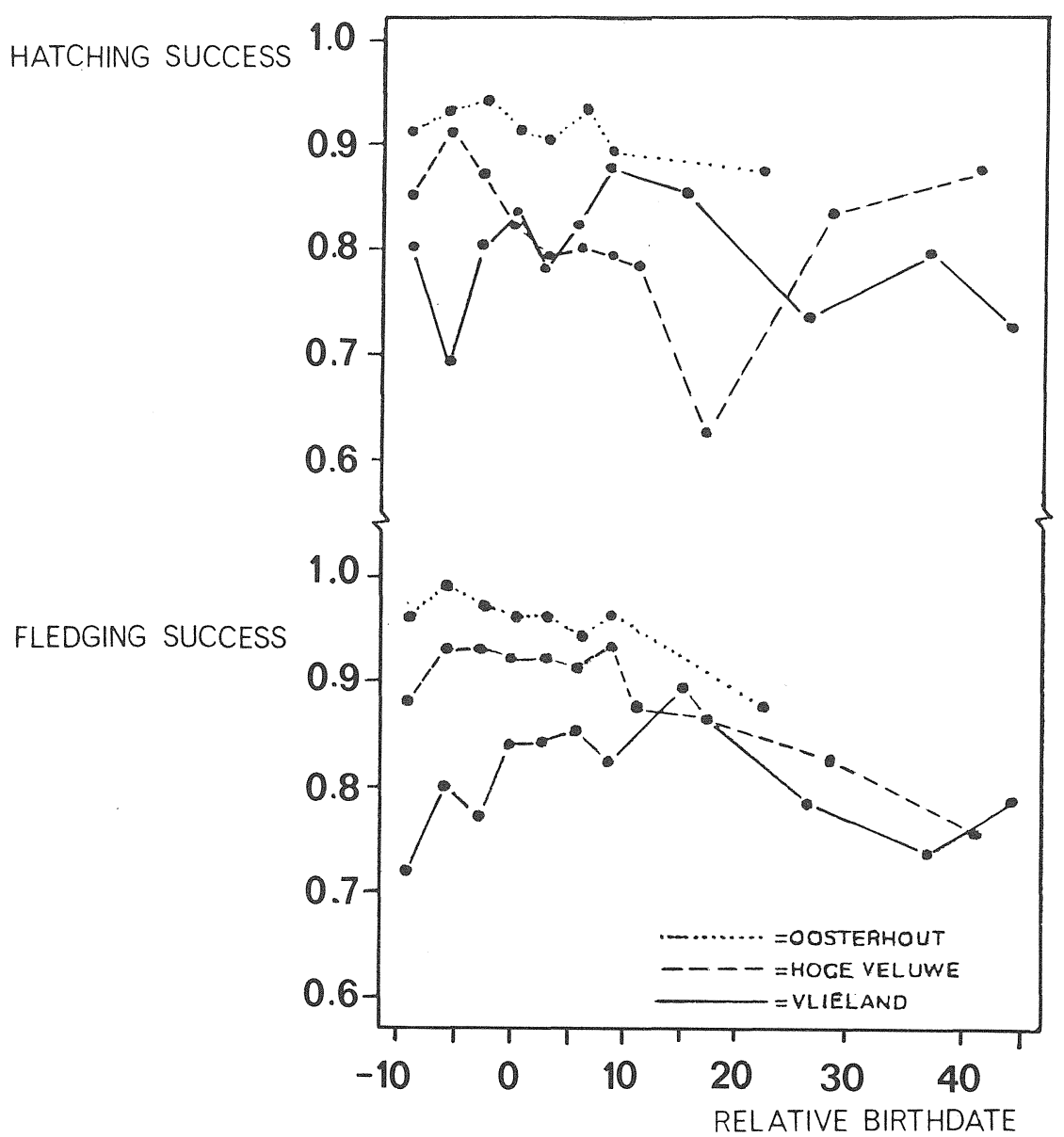

Fig. 7. Hatching and fledging success of Blue Tit broods in relation to their relative hatching date. $0=$ mean hatching date of the first broods in the year concerned. Repeat and second broods have relative hatching dates of 25 and over.

significant variables are eliminated, in which case $r^{2}$ for both hatching and breeding success is highly significant. In the mixed forest at Hoge Veluwe the same correlation holds, and in addition there is a positive correlation with mean laying date: hatching success is higher in late years. When breeding density is left out, there is also a relationship between hatching success and year number: hatching success decreased in the course of the study period, as already shown. This relationship was also found in the Vlieland data. Moreover, in this area, fledging success appeared to be negatively related to clutch size, suggesting that in years with large broods the tits are not so successful in rearing their young to fledging as in years when broods are smaller. 
Table VIII. Results of multiple regression analysis of hatching success (HS), fledging success (FS) and breeding success (BS) in three areas. Data from 1965 - 1986, except years with $<5$ broods. Regression coefficients and $r^{2}$ are given with their significance. $(*): \mathrm{p}<.10, *: \mathrm{p}<.05, * *: \mathrm{p}<.01, * * *: \mathrm{p}<.001$.

\begin{tabular}{|c|c|c|c|c|c|c|}
\hline \multicolumn{2}{|l|}{ Area } & year & laying date & clutch size & density & $\mathrm{r}^{2}$ \\
\hline \multirow[t]{3}{*}{ Oosterhout } & HS & -.0015 & -.0004 & $+.0397 *$ & +.0001 & .3982 \\
\hline & FS & -.0011 & +.0001 & +.0152 & -.0013 & .2218 \\
\hline & $\mathrm{BS}$ & -.0026 & -.0002 & $+.0517 * *$ & -.0006 & $.4357\left(^{*}\right)$ \\
\hline \multirow[t]{3}{*}{ Hoge Veluwe } & HS & -.0025 & $+.0041 * *$ & $+.0301 * *$ & -.0056 & $.7429 * * *$ \\
\hline & FS & +.0002 & +.0005 & +.0148 & -.0060 & .2001 \\
\hline & BS & -.0014 & +.0041 & $+.0410^{* *}$ & -.0135 & $.4868 * *$ \\
\hline \multirow[t]{3}{*}{ Vlieland } & HS & $-.0053 *$ & +.0030 & -.0181 & +.0480 & .3133 \\
\hline & FS & +.0019 & -.0022 & $-.0939^{*}$ & -.0409 & .2872 \\
\hline & $\mathrm{BS}$ & -.0035 & +.0006 & -.0880 & +.0100 & .1745 \\
\hline
\end{tabular}

There were no significant relationships between breeding density and the various measures of breeding success.

Apart from the effect of predation and disturbance on total losses, we have seen that breeding success differs in the three areas, and that it depends on local rather than general conditions. The differences in the seasonal changes in breeding success, declining in Oosterhout and Hoge Veluwe and increasing in Vlieland, agree with this view. These conditions may be similar in the egglaying and the incubation period, as clutch size and hatching success are positively correlated. Food availability may be a prominent factor.

\section{SECOND BROODS}

A summary of the occurrence of second broods in the areas for which we have sufficient data is given in Table IX. The percentage of second broods increases from Oosterhout to Hoge Veluwe, and is very high in Vlieland. The interval between the mean laying dates of first and second broods increases from 38.8 days in Oosterhout to 41.8 days in Hoge Veluwe and to 44.8 days in Vlieland (Table X). Hence, for the average Blue Tit, the breeding season lasts much longer in Vlieland than in the other areas.

Earlier we have seen that the decrease in clutch size within the first broods is much less steep in Vlieland than in the other areas. In this respect it is striking that the number of eggs in repeat and in second clutches is larger in Vlieland than in the other areas (Table X). Presumably conditions do not deteriorate as quickly as in the other areas. 
Table IX. Percentage of second broods in three Blue Tit populations. Data from $1965-1986$.

\begin{tabular}{|c|c|c|c|c|c|}
\hline \multirow[t]{2}{*}{ Area } & \multirow{2}{*}{$\begin{array}{l}\text { no. of } \\
\text { successful } \\
\text { first broods }\end{array}$} & \multirow{2}{*}{$\begin{array}{l}\text { no. of } \\
\text { second } \\
\text { broods }\end{array}$} & \multicolumn{3}{|c|}{ percentage second broods } \\
\hline & & & mean & $\min$. & $\max$. \\
\hline Oosterhout & 343 & 12 & 3.5 & 0 & 20.0 \\
\hline Hoge Veluwe & 668 & 64 & 9.6 & 0 & 25.6 \\
\hline Vlieland & 457 & 170 & 37.2 & 10.0 & 100.0 \\
\hline
\end{tabular}

Table X. Mean laying date and clutch size of first, repeat and second clutches of the Blue Tit in three areas. Data from 1965 - 1986.

\begin{tabular}{|c|c|c|c|c|c|c|c|c|c|}
\hline \multirow[b]{2}{*}{ Laying date } & \multicolumn{3}{|c|}{ first } & \multicolumn{3}{|c|}{ repeat } & \multicolumn{3}{|c|}{ second } \\
\hline & mean & S.D. & $\mathrm{N}$ & mean & S.D. & $\mathrm{N}$ & mean & S.D. & $\mathrm{N}$ \\
\hline Oosterhout & 19.6 & 6.4 & 386 & 44.3 & 12.2 & 20 & 58.4 & 5.6 & 12 \\
\hline Hoge Veluwe & 26.2 & 6.8 & 749 & 51.0 & 11.5 & 54 & 68.0 & 6.4 & 62 \\
\hline Vlieland & 26.3 & 6.0 & 553 & 54.9 & 8.9 & 44 & 71.1 & 8.2 & 155 \\
\hline Clutch size & mean & S.D. & $\mathrm{N}$ & mean & S.D. & $\mathrm{N}$ & mean & S.D. & $\mathrm{N}$ \\
\hline Oos & 11.5 & 1.56 & 386 & 7.7 & 2.00 & 20 & 6.8 & 0.97 & 12 \\
\hline Hoge Veluwe & 10.5 & 2.24 & 749 & 6.9 & 2.19 & 54 & 6.9 & 1.42 & 62 \\
\hline Vlieland & 11.1 & 1.53 & 553 & 8.7 & 2.62 & 44 & 7.8 & 1.50 & 155 \\
\hline
\end{tabular}

\section{DISCUSSION}

Ten years ago Perrins (1979) stated that the Blue Tit is basically a bird of broad-leaved deciduous woodland, especially oakwoods. That this species is well-adapted to oakwoods is confirmed by the present study: the breeding density is high and relatively stable, clutches are large and eggs are laid early in the season, and breeding success is higher and less variable than in the other habitats. The fact that egg-laying dates in oakwoods are not only earlier but also more variable between years, means that the factors to which Blue Tits respond are more variable in oakwoods than in mixed woods.

These findings on the differences in breeding density, laying date, clutch size and breeding success in different habitats confirm the results obtained by other authors (Gibb 1950, Lack 1955, 1958, Dhondt et al. 1984).

Having established that the Blue Tit is well-adapted to conditions in deciduous oak woodland, it becomes most interesting to study in which ways populations in other, contrasting habitats, such as conifer plantations or evergreen oak woodland, differ from the populations in deciduous oak woodland. 
This is especially interesting where there are evident differences in timing of the breeding season (cf. Blondel et al. 1987).

In the mixed forests studied by us the Blue Tits usually nest in or close to deciduous plots or patches of deciduous trees that are surrounded by conifers. On the one hand this suggests that there is a preference for deciduous habitat, but on the other hand this does not preclude the fact that breeding success is much lower than in oakwood.

The island population of Vlieland deviates from the mainland populations in several respects: it is a fairly young population ( $<50$ years old), with a low but sharply increasing density, hardly any decline of clutch size (in first clutches) with laying date, low breeding success, and an increase of breeding success (in first broods) with date. Moreover, many birds produce a second clutch (cf. the findings by Winkel (1975) in a larch forest in Germany). Some of these phenomena are similar to those found for Great Tits in pine plantations. The latter birds time their breeding season in a way similar to their conspecifics in oakwood, but the peak in food (caterpillar) availability is several weeks later in the pine than in the oakwood. This results in heavy nestling mortality and low fledging weights (van Balen 1973). Indications that such a situation also applies to the Blue Tits in Vlieland are twofold: in 1988 the peak in caterpillar abundance in the oaks in Vlieland occurred about 9 days later than in the oaks in Hoge Veluwe, and the distribution of the small patches of deciduous trees (where most of the Blue Tits nest) in Vlieland is such that the tits' nests are close to large blocks of conifers. Many of the peculiarities of the Blue Tits can be understood if one assumes that much of the food is collected in the conifer plantations. Observations on foraging behaviour are, however, lacking.

Breeding success, calculated as the number of fledglings per egg laid, is invariably high in deciduous oak woods (Table VII and Gibb 1950, Lack 1955, 1958, Källander 1983), and considerably lower in mixed forest, evergreen oaks, conifers, and gardens (e.g. Blondel et al. 1987, Cowie and Hinsley 1987).

The relationship between breeding success and hatching date differed strikingly in the three study areas: in Oosterhout and Hoge Veluwe breeding success declines with date, as has been found before by Perrins $(1965,1970)$ for the Great Tit in Wytham and by van Balen (1973) for the same species in Oosterhout and Liesbos. In Vlieland, however, breeding success was largest for late first broods. In two Dutch pine plantations the seasonal trend in Great Tit fledging success varied from year to year in correspondence with the timing of the peak of food availability, and success often peaked in the second half of the breeding season (van Balen 1973). Moreover, van Noordwijk et al. (1981) found that selection for laying date in the Great Tit in Hoge Veluwe and Vlieland was variable from year to year, sometimes favouring early, and sometimes middle or late first broods. In Vlieland late first broods were favoured in many years. It is evident that the relationship between reproductive success and date does not follow general rules, but that it is to a large extent determined by local conditions, e.g. the seasonal trend in food availability. In the Blue Tit, parental survival and recruitment need to be studied before we can draw definite conclusions about timing and parental fitness.

One could ask if the population in Vlieland has shown any changes through the years indicating an increasing degree of adaptation to the new 
environment. However, apart from the breeding density, that increased sharply until 1977 and stabilised thereafter (Fig. 1), there were no apparent changes, either in laying date, or in clutch size, breeding success or proportion of second broods.

Earlier it was shown that hatching success declined significantly over the years in Hoge Veluwe and Vlieland. This can be associated with the presumed occurrence of calcium shortage in the eggshells of Great Tits and several other passerines, that has been recently observed in Buunderkamp, another study area with coniferous and mixed deciduous forest on poor sandy soils. Here, the percentage of females without eggs or with eggs of inferior quality has increased sharply in recent years (Drent and Woldendorp 1989). Observations made in 1989 have shown that egg volume and eggshell weight in the Great Tits from Hoge Veluwe are slightly larger than the values for Buunderkamp, but lower than in Oosterhout and Liesbos (Graveland, pers. comm.). It seems fairly certain that the decline in hatching success observed in Hoge Veluwe and Vlieland is caused by calcium shortage, which is presumably related to acid precipitation.

We concluded earlier that short-term density changes are often correlated between areas, and must be determined to a large extent by general, rather than local factors, among which winter severity probably is prominent. Combining this conclusion with the finding that density is more variable in the low-density than in the high-density areas, it seems that Blue Tits in less favourable areas suffer more from cold in winter than birds in the favourable deciduous oak woodland.

By comparing the annual values for different areas it was found that changes in breeding density and laying date are influenced by general rather than local factors, whereas the reverse applies to clutch size and breeding success. This implies that in studies of clutch size or breeding success differences between areas must be taken into account: patterns like annual and seasonal variation in these parameters do indeed vary between areas.

The fact that breeding success is determined by local factors, but changes in breeding density are influenced by general factors implies that most of the local variation in productivity is removed by factors operating after fledging. For the Great Tit the beechmast crop and winter severity play an important role because of their effect on juvenile survival (van Balen 1980). The size of the beech crop probably has little effect on Blue Tit numbers, although Källander and Karlsson (1981) have found significant correlations between population size and beechmast crop in two out of three areas. Winter severity has an evident effect as was also found by Källander and Karlsson (l.c.). Further study is needed to find out which feeding resources are important for juvenile survival of this species.

There are several indications that competition between Great and Blue Tits affects density or breeding parameters of the Blue Tit. The opposing density figures of the two species in Vlieland-West and -East agree with findings by Dhondt and Eyckerman (1980), who concluded that Blue Tit breeding numbers were influenced by competition with Great Tits for roosting sites in winter. The correlation between Great Tit or Blue Tit density and the difference in laying date between the two species, that was found in two areas, 
could mean that either the Blue Tit lays earlier or the Great Tit later in years with a high density of competitors, this leads to a lower intensity of competition. Further research is needed to find out whether the Blue Tit or the Great Tit or both respond to this.

Dhondt et al. (1984) argued that differences in laying date are probably caused by differences in the timing of food availability. Regarding the difference in timing between Great and Blue Tit, as related to density, one could argue that Blue Tits would take smaller prey in the egg-laying period, as they do later (Török 1986). Blue Tits would prey on the early stages of caterpillars, leaving less prey of adequate size for Great Tits. This could result in delayed egg-laying by Great Tits at high Blue Tit density.

\section{ACKNOWLEDGEMENTS}

This study could not have been made without the dedicated efforts of many workers in the field, notably H.M. van Eck, J. Visser and D. Westra. We thank A.J. Cavé, P.J. Drent, J.M. Tinbergen and S. Verhulst for helpful comments on the manuscript.

\section{REFERENCES}

Balen JH van (1973) A comparative study of the breeding ecology of the Great Tit Parus major in different habitats. Ardea 61: 1-93

Balen JH van (1980) Population fluctuations of the Great Tit and feeding conditions in winter. Ardea 68: 143-164

Berndt R, Winkel W, Zang H (1983) Über Legebeginn und Gelegestärke von Kohl- und Blaumeise (Parus major, P. caeruleus) in Beziehung zur geografische Lage des Brutortes. Vogelwarte 32: 46-56

Blondel J, Clamens A, Cramm P, Gaubert H, Isenmann P (1987) Population studies on tits in the mediterranean region. Ardea 75: 21-34

Cowie RJ, Hinsley SA (1987) Breeding success of Blue and Great Tits in suburban gardens. Ardea 75: 81-90

Dhondt AA, Eyckerman R (1980) Competition between the Great and the Blue Tit outside the breeding season in field experiments. Ecology 61: 12911296

Dhondt AA, Eyckerman R, Moermans R, Hublé J (1984) Habitat and laying date of Great and Blue Tit Parus major and P. caeruleus. Ibis 126: 388397

Drent PJ, Woldendorp JW (1989) Acid rain and eggshells. Nature 339: 431

Gibb J (1950) The breeding biology of the Great and Blue Titmice. Ibis 92: 507539

Kluyver HN (1951) The population ecology of the Great Tit, Parus m. major. Ardea 39: 1-1.35 
Kluyver HN (1971) Regulation of numbers in populations of Great Tits (Parus m. major). Proc Adv Study Inst Dynamics Numbers Popul (Oosterbeek 1970): 507-523

Källander $\mathrm{H}$ (1983) Aspects of the breeding biology, migratory movements, winter survival, and population fluctuations in the Great Tit Parus major and the Blue Tit $P$. caeruleus. Thesis, Univ of Lund

Källander H, Karlsson J (1981) Population fluctuations of some North European bird species in relation to winter temperatures. Proc Second Nordic Congr Ornithol 1979: 111-117

Lack D (1955) British tits (Parus spp.) in nesting boxes. Ardea 43: 50-84

Lack D (1958) A quantitative breeding study of British tits. Ardea 46: 91-124

Noordwijk AJ van, van Balen JH, Scharloo W (1981) Genetic variation in the timing of reproduction in the Great Tit. Oecologia 49: 158-166

Perrins CM (1965) Population fluctuations and clutch size in the Great Tit, Parus major. J Anim Ecol 34: 601-647

Perrins CM (1970) The timing of birds' breeding seasons. Ibis 112: 242-255

Perrins CM (1979) British Tits. Collins, London

Schmidt K-H (1984) Frühjahrstemperaturen und Legebeginn bei Meisen (Parus). J Orn 125: 321-331

Schmidt K-H, Steinbach J (1985) Jahreszeitliche Änderung der Gelegegrösze bei der Kohlmeise (Parus major)? J Orn 126: 163-173

Török $J$ (1986) Food segregation in three hole-nesting bird species during the breeding season. Ardea 74: 129-136

Winkel W (1975) Vergleichend-brutbiologische Untersuchungen an fünf MeisenArten (Parus spp.) in einem niedersächsischen Aufforstungsgebiet mit Japanischer Lärche Larix leptolepis. Vogelwelt 96: 41-63, 104-114 